\section{Ethnic minorities and the Mental Health Act ${ }^{\dagger}$}

\author{
GLYNN HARRISON
}

Compulsory detentions under Part II of the Mental Health Act are six times more likely to be of Black people than of White. This headline statistic (Audini \& Lelliott, 2002, this issue) will provide rich pickings for inflammatory journalism and exploitative political comment. Experienced observers are familiar with a predictable cycle of events. First, data like these are spotted by a journalist and, in their crude and uninterpreted form, used as fodder for talking heads and the re-grinding of axes. Numerous issues are drawn into the debate, some relevant, many not. Then, as the complexity of the data begins to emerge, public attention lapses and the debate moves on. Professionals are left demoralised and stigmatised; users and carers find themselves confused, suspicious and further alienated from the services they need.

\section{ARE THESE FINDINGS RELIABLE?}

The issues raised by Audini \& Lelliott, and other authors before them, are too important to be sensationalised in this way. There are several relevant questions about these findings. First, are they reliable? A systematic review of the literature relating to the Mental Health Act (Wall et al, 1999) revealed a fairly consistent pattern, extending over the past dozen years at least. The evidence is now compelling that rates of compulsory detention in the UK are higher in those of African-Caribbean family background and, to varying degrees, higher also in some other ethnic minority groups. Audini \& Lelliott suggest that crude rates of compulsory admissions under Part II of the Act, unadjusted for diagnosis, may lie toward the upper end

†See pp. 222-226, this issue. of the range of previous studies: somewhere between a two-fold and a six-fold increase.

All of these studies have methodological weaknesses and sources of bias. For example, there are different-and sometimes contentious - methods for defining 'ethnicity', and evidence of unreliability in methods of data collection. Many studies have to make sense of information about ethnicity that is categorised and collected in a variety of ways across different data-sets. Few have been able to adjust for repeat admissions. All are subject to problems of under-enumeration in the denominator population. However, despite these weaknesses, there is a consistency of association across studies. It is possible to avoid one or two rocks falling down a hillside, but when several are tumbling in the same direction we may be dangerously close to an avalanche.

\section{HOW SHOULD THESE DATA BE INTERPRETED?}

Oversimplification of data using polarised definitions of ethnicity and compulsory admission can be potentially inflammatory. Crude rates of compulsory admissions by ethnicity, unadjusted for diagnosis and other socio-demographic factors, need careful scrutiny. If rates are adjusted for diagnosis, differences are much smaller. Studies investigating rates of compulsory admission in patients with psychoses, for example, report the ratio in the proportions of formal admissions of Black $v$. White patients as 1.5-2 (Davies et al, 1996). So diagnosis is a critical issue, and several factors need to be taken into account.

We can now be reasonably certain that incidence rates for psychotic disorders in British-born individuals with an AfricanCaribbean family background are significantly elevated - studies suggest that these rates are approximately 2-8 times greater (Eaton \& Harrison, 2000). We know, too, that rates of compulsory detention among patients with psychoses are high. Thornicroft et al (1998) found that among 500 patients with psychoses, over $50 \%$ had been admitted under the Mental Health Act at least once in the course of their illness. Headline rates for 'Black people' are thrown further into perspective by evidence of a general rise in the absolute number of admissions under the Mental Health Act between 1984 and 1994, and (probably) a disproportionate increase in inner-city areas. In inner urban areas at least, most patients with a psychotic illness are likely to experience detention under the Mental Health Act at some point in their illness. Many will come from the ethnic minorities more likely to live in such areas.

\section{SO IS THERE A PROBLEM?}

In The Netherlands, although there is a similar elevation in the rate of schizophrenia among migrants from The Netherlands Antilles and Surinam, preliminary data suggest there is no significant increase in compulsory detentions among those so diagnosed after taking into account age and gender (Selten \& Sibjen, 1994). In the UK, however, the evidence overall suggests that although differences in rates of compulsory admission are narrowed after taking diagnosis into account, people with an African-Caribbean family background and with a psychotic disorder remain more likely to be detained under Part II of the Mental Health Act (Wall et al, 1999). Given the potential public interest of these findings, and the length of time over which they have been reported, it is all the more surprising that there has been relatively little commissioned research in this area. None of the published studies secured a sample large enough to allow thorough analysis of potential confounding due to age, social deprivation, substance misuse and diagnostic differences. Moreover, there has been little culturally sensitive research into key determinants operating across pathways to care in different ethnic groups. This state of affairs applies to research into the Mental Health Act as a whole: Department of Health data are unreliable and have been neither widely disseminated nor subjected to extended analysis (Wall et al, 1999). Data provided by local authorities are difficult to interpret because of poor standardisation of data extraction, missing values and different definitions of ethnicity. 
There has also been little work on the use of Part $\mathrm{X}$ of the Act in ethnic minorities. As we wade through this sea of ignorance, patients continue to be exposed to the potential adverse consequences of compulsion: alienation from services, poor concordance with both physical and psychological treatments, and lengthy durations of untreated psychosis. This is a tragedy for the community and one of the most pressing challenges to the practice of psychiatry in inner-city areas.

\section{POLICY IMPLICATIONS}

Three policy decisions need to be made if we are to escape this cycle. First, we must shake up the way in which routine data are collected, centralised and analysed. This will require a sustained and coherent programme that crosses the boundaries between health care and social care. The new Mental Health Act offers an opportunity to develop robust mechanisms for monitoring activity and analysing trends. The minimum data-set provides a further opportunity for the collection and analysis of patient-level data.

Second, it is time to commission research with study designs and sample sizes that will convincingly address the problems of confounding and case definition. Service users from different ethnic groups should be involved in their planning, fieldwork and analysis. Researchers need to demonstrate sensitivity to questions relevant to users and carers as well as to those who must deliver evidencegrounded health care. We need qualitative methods too. These can be nested in larger-scale quantitative studies, examining the role of cultural factors in access to care, pathways through services, duration of untreated psychosis and potentially racist attitudes operating in the service. We also need to understand what 'culturally sensitive' services actually look like.

Finally, is the time now right for the introduction of a target to reduce the proportion of people with an African-Caribbean background treated under the Mental Health Act? This proposal has some merit, but the arguments are finely balanced. Rates of compulsory detention vary significantly between different centres and targets

GLYNN HARRISON, FRCPsych, Division of Psychiatry, University of Bristol, Cotham House, Cotham Hill, Bristol BS6 6JL, UK. Tel: +44 (0)II7 9546665

(First received 20 April 200I, final revision 20 August 200I, accepted I October 200I)

can produce perverse incentives, not least the risk that some patients could remain untreated. Given our lack of knowledge about the factors driving these high rates of compulsory admission, it would be reckless to embark on an ill-conceived programme that could have repercussions in terms of safety. Furthermore, the quality of much routine data remains poor, with little capacity and insufficient resources in the system to address this. Mental health services have been promised funding for new initiatives in the past, only to see the money drain elsewhere. On the other hand, a realistic target could galvanise new partnerships, provide earmarked funding for inner-city mental health services, and drive forward the introduction of data systems that we could begin to trust. There are probably three fundamental requirements for a targeting policy: realistic planning, earmarked funding and local ownership. A carefully managed process would be required, with adequate piloting. The first step would be to require each health and social care community to produce valid and reliable data on its rates of compulsory admission against agreed and nationally specified criteria for key variables such as ethnicity and diagnosis. These data would need to pass robust quality-control checks. Then, to enhance local ownership and engagement, rather than impose a national target, each area could be asked to develop and agree a local target. These targets could be published as part of a national benchmarking exercise and earmarked funding linked to the quality and credibility of the plan. Service users and carers would need to be fully involved. New ideas would be required for culturally relevant (but evidence-grounded) service styles, family engagement and models of assertive outreach. Training in race awareness, presently carried out in an ad boc manner in the different professions, could be developed and grounded by focusing on the key issues at each point of the care pathway. The potential for unwitting racism becoming institutionalised in local processes of compulsion could be investigated and challenged, alongside opportunities to root out more explicit and stereotyped racist attitudes (Sashidharan, 2001).

Such a complex operation would not be without its risks and, given the parlous state of some inner-city mental health services, may appear hopelessly unrealistic. The prize, however, would be local initiatives, planned and implemented through local partnerships, with 'trickle-down' benefits for service development as a whole. A realistic target would also send a clear signal to members of the Black community that their needs are being taken seriously.

\section{DECLARATION OF INTEREST}

None.

\section{REFERENCES}

Audini, B. \& Lelliott, P. (200I) Age, gender and ethnicity of those detained under Part II of the Mental Health Act 1983. British Journal of Psychiatry, 180 222-226.

Davies, S., Thornicroft, G., Leese, M., et al (1996) Ethnic differences in risk of compulsory psychiatric admission among representative cases of psychosis in London. BMJ, 312, 533-537.

Eaton, w. W. \& Harrison, G. (2000) Ethnic disadvantage and schizophrenia. Acta Psychiatrica Scandinavica, 102 (suppl. 407), I-6.

Sashidharan, S. P. (200I) Institutional racism in British psychiatry. Psychiatric Bulletin, 25, 244-247.

Selten, J. P. \& Sibjen, N. S. (1994) First admission rates for schizophrenia in immigrants to the Netherlands. Social Psychiatry and Psychiatric Epidemiology, 29, 7I-77.

Thornicroft, G., Strathdee, G., Phelan, M., et al (1998) Rationale and design. PRiSM Psychosis Study I. British Journal of Psychiatry, 173, 363-370.

Wall, S., Churchill, R., Hotopf, M., et al (1999) $A$ Systematic Review of Research Relating to the Mental Health Act (1983). London: Department of Health. 